\title{
From Perception to Change. A Model for Prevention Communication
}

\author{
Andrea Volterrani
}

University of Rome Tor Vergata

\begin{abstract}
The paper presents and discusses a model for prevention communication in relation to natural disasters based on the Italian campaign, "I do not take risks." The model consists of: a) the four stages of change in the prevention communication process: 1) perception and relevance: how to perceive an issue or significant problem, 2) knowledge: how to deepen the characteristics of the issue or problem that an individual considers relevant, 3) incorporation: how does one incorporate the issue into the imaginary, 4) change: how one can change behaviors and attitudes; b) the four principles of daily work for the prevention of communication: 1) monitor the media on a daily basis, 2) read the public space, 3) deal with the operators of information, 4) analyze the media landscape of the theme; c) the five dimensions of communication prevention strategy: 1) popularity in the messages, 2) use of narratives, 3) ritual in communication actions, 4) colonizing the imaginary: imaginary appropriation of market communication, 5) media education: building knowledge and awareness among citizens; d) the four phases of prevention communication impact assessment: 1) objectives, 2) community analysis, 3) measurement of involvement and participation, 4) impact assessment.
\end{abstract}

Keywords: Prevention Communication, Natural Disaster, Change

\section{Introduction}

Cultural change has always been a central focus of social analysis. Understanding how and what symbols, values, and behavior change is to understand in depth changes and social innovations.

Communication is the catalyst and the core of this change, but often because of its characteristic of seeming naturalness, each individual and community tends to overlook and minimize the visible and invisible potential of communicative actions (Couldry, 2012).

This potentiality and intrinsic characteristic is even more important for prevention communication. In fact, if communication is the main focus in the change in the buying patterns market, along with the strengthening and visibility of the brand, what often comes into play in prevention communication is the identity change of both the individual and collective.

Furthermore, the object of change issues is often controversial and contradictory - for example, there may be communication campaigns to counter the risk of pathological gambling, yet there are also explicit and implicit messages inviting you to "try your luck" in some state lottery - from both scientific and common sense points of view, and sometimes, from a moral one as well (e.g., a campaign against homophobia which urges people who have very different value-convictions on the subject to change their opinion). Three different aspects - science,

Corresponding Author E-mail: andrea.volterrani@uniroma2.it 
common sense, and morality - involving differentially individual and collective social imaginary (Jedloswki, 2008, p. 134).

This is the first reason why coming up with and planning prevention communication is not simple: when you touch things that are part of our deepest convictions or which are taken for granted in our daily lives, every fact, interpersonal communication, or media that tends to problematize, you do not have an easy time of it. The "roots" of imagination are deep and firm, and are unlikely to be affected unless specific events capable of subverting ideas, meaning, and linked images occur. From this we must try to understand the change of social imaginary processes.

\section{The processes of change: a focus}

The changes that can be connected to prevention communication are neither simple nor immediate. But in order to start an argument that is not just fatalistic, we must try to analyze the process that could lead to changes in the experienced reality. At least four different stages have been identified: a) the perception, selection, and relevance of the topic or issue; b) knowledge of the topic or issue; c) the incorporation of the issue or problem; d) the possible change of attitudes and behavior in relation to the issue or problem (Figure 1).

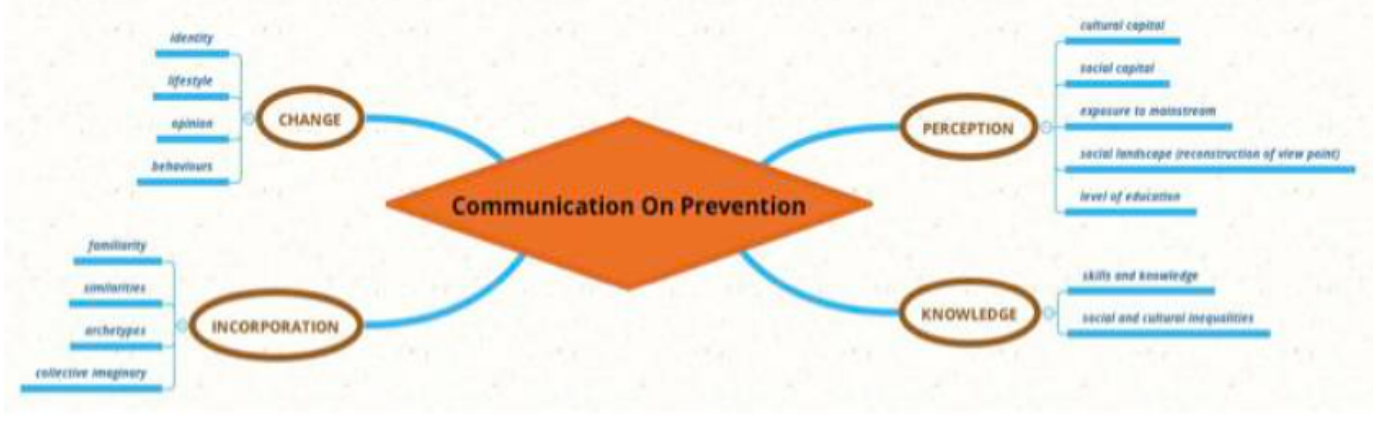

Figure 1 Model of communication on prevention

a. Perception of the theme. The perception of the subject by an individual is an important step. For example, I may be horrified by a car accident, but do not feel that I can be involved if I do not adopt a different behavior. However, finding that particular communication process which makes me "turn on" my eye is not easy. Seeing what is and what is not relevant to me from among the countless communication processes around me is the first step. Beyond the theories of persuasion that emphasize the ability to build messages that are more noticeable than others, the issue at stake here is another: what are the selective processes that cause a priority issue, a problem, to be strongly tied to my identity aspect, my behavior, and my attitudes? In the above example, it is not easy to see what image or video, such as sequences, or which safety problem in the road driving narrative will be most able to make me turn on the selection. The processes by which we interpret and select media content are very complex (Couldry, Livingstone, Markham 2010). One on which it is important to dwell is that the role of individuals, and the communities to which they belong, is an established element in the interpretation to be taken into account in prevention communication. It is a delicate phase that is not attributable only to the visibility of the issue or problem, but also to the ability and symbolic resources that individuals possess. These are not distributed evenly within the population nor do they reproduce the same social and territorial family and economic contexts. Next comes the problem of cultural inequalities at stake (Bentivegna, 2009S), a problem which, along with that of social inequalities, has been too often overlooked or relegated to the margins of reflection in recent times. If I do not have sufficient or adequate cultural and symbolic resource perception, the significance and the selection will be strongly affected, and in some cases, severely limit the opportunities that could be seized. For example, it is known that good nutrition prevents serious health problems. However, it is 
also known that those who have greater economic and cultural deprivation tend to underestimate the problem, and thus poor nutrition adds further problems to existing problems.

b. Knowledge. This aspect is closely linked to the second phase of the process of change, knowledge. The transition from the perception of the theme's relevance to knowledge is primarily a growth of awareness of the need to deepen, individually or collectively, a certain aspect in which I / we are concerned. In this case as well the path is not deterministic but connected to both the characteristics and individual resources that are available across all media and interpersonal relationships. Neither aspect can be taken for granted but, in fact, possess considerable difficulties, even when everything else would tell us otherwise. A striking example is the knowledge that should result from communication processes in risk or crisis situations due to natural disasters. Even in those moments which are critical for physical survival, the initial problematization does not automatically switch to the knowledge of what should be done (Horsley, 2016). Despite seismic risk awareness, few of us remember that there are small things you can do in your own home, such as securing everything on the walls. Those involved in risk communication and prevention tried to come up with and plan complex models that provide a strong activation of local communities and a strong involvement of people who could potentially be interested in such knowledge with particular reference to the most vulnerable social situations (Volterrani, 2016). For example, the involvement of people with disabilities may not only be "on paper," but stem from a detailed one-to-one relationship that increases the degree of risk knowledge and the consequent ability to implement what is necessary in order to prevent.

c. Incorporation. Knowledge alone, however, is not sufficient to prompt a possible action. The next step is incorporation. Some scholars of cognitive psychology (Hofstadter, Sander 2015) have highlighted the way in which humans expand their wealth of concepts and terms in their own world of thought. The tool we use to categorize the outside world is the analogy, i.e., reading the external environment with the categories we already have in our heads and in our daily life experience. The incorporation of new concepts and new experiences is through comparisons and comparisons (note similarities) with what we have in our heads and what we think comes closest to the new issue we are facing. It is evident that absolute novelty will have more difficulty of being incorporated than new minor or simple variations on already known themes and problems. For those not raised in Italy, the bidet is an object and a concept which is not easy to incorporate (or even to comprehend), but it is easier than trying to imagine what it is like to make a crossing without economic resources in the hold of a jam-packed boat always on the verge of sinking. It is perhaps the most important aspect of the change through the communication process because it leaves little room for innovation and deep trends. We tend to consolidate what we know well and distrust what we do not know. No wonder this reasoning because the survival of the species is closely linked to the ability to read and assess the dangers posed by the unknown. The archetype of fear of the new and different is rooted in our collective imagination and is an integral part of human history (Durand, 1960). This does not mean that we do not possess the cultural tools to overcome this archetype, but, returning to the reflections on cultural inequalities, it is unthinkable that we all possess the same means. It is much easier to say, "We've always done well" or "There is nothing much to do; it's fate" than evaluate alternatives and possibilities, build visions and different horizons (Vergani, 2012) on the subject or the problem to be addressed.

d. Change. The fourth and final phase is the action of change. This is a delicate phase because the action of change may have effects on both the individual and collective level and can be real or imaginary. Individual change is more complex because it involves a "revolution" in the behavior or attitudes of our daily lives. If we think of how challenging it is, for example, for individual smokers to quit smoking despite a large presence of information and empirical evidence, we can understand that this step, which is often considered to be "simple," has, however, many elements of complexity to be explored. The most common expression is, "I want to stop smoking because it's bad for me, but I can't." Another argument is the change of the collective imagination which, though complex, can be achieved more easily. In fact, this is closely connected with local cultural change 
or the collective imagination on the subject. Also in the case of smoking, the growing prohibition of spaces available for smokers has been "accepted" as a positive change, even by smokers themselves, without protest.

The process of change can be connected to prevention communication, and therefore, is complex and articulated. If we add to the difficulties of interpersonal and media communication processes that are now an integral part of the studies on the audience (Murray et al, 2003), we understand that the challenge is difficult but very attractive to those who care about improving the quality of life of our communities.

\section{The problem / opportunities of the mainstream}

Reasoning on the change in the communication process means, therefore, trying to operate in order to innovate the public imagination in the direction of an enlargement of the symbolic resources available to individuals and communities of often complex and contradictory issues and problems, such as social ones. Opening the imaginary means making the images, ideas, and values that would otherwise remain marginal in our heads available and accessible to most people.

The mainstream is defined as the medial cultural production (cinema, television series and serials, video games, and communications products) hegemonic in contemporary societies; namely, that set of behaviors, attitudes, and meanings to which we refer, even unknowingly (Martel, 2010), and which remain in our collective imagination, so as to occupy almost all the space, especially if we pause to assess the large overlap with common sense in contemporary society. Many features of contemporary common sense are produced by the mainstream media, which feed and reinforce ways of speaking and thinking, lifestyles. This is not to make a generic accusation of superficiality and banality in the mainstream but, rather, to highlight the potential role it plays in people's lives. Socialization, first of all, against those who have lifestyles, and especially of consumers in the western world. Anticipation of what the future might be, or rather the idea of the individual and collective future. It is an imaginary reserve from which to draw inspiration for the construction of identity (Silverstone, 1994). It is evident that prevention communication, as we have described it up to now, can not remain on the periphery of the mainstream, can not build a symbolic universe apart, but must instead promote a real colonization using homogeneous technical and quality standards and which is likely to contaminate and replace, symbolically and culturally, the mainstream. A positive example of the process of change in the mainstream is that of the perception of the care of the environment as a determinant for overall well-being (Peruzzi, Volterrani 2016, p. 150). Despite that the conduct is not always consistent, ecological awareness has reached the heart of the mainstream within the last thirty years. The same reasoning can not be said of the rampant issue of child poverty in African countries where the awareness has not turned into incorporation, or indeed, produced the "stolen letter effect;" that is, objects that are right in front of everyone's eyes but go unnoticed.

Precisely for this reason it is even more necessary to share this vision of prevention communication in a cultural context which is often used to think that the important issues are very different.

All of this is adversely affected if we design prevention communication with a completely different approach from the other types of communication: participation.

\section{Participatory prevention communication: an essential prerequisite}

Prevention communication can not exist without the participation of the holders of the problem, the interests of users, and the producers of communication. A triangle that is crucial if we want to trigger at least the start of the change processes we mentioned. If you want to increase blood donation among young people, it is not enough to just construct communications campaigns "aimed" at them, but to also construct occasions where the young people themselves are the protagonists. 
Engagement is not just an observation of a different use of the media by the public, but one of the roads that promotes awareness and involvement in the citizens of a community (Dahlgren, 2009; 2013). And it is the first step before moving on to the knowledge, incorporation, and action for change.

Participation needs its own time and its own rules (Curran, 2011), to give space to all those who intend to take action. However, in prevention communication that does not mean slowing down but enriching and articulating content and mode of use.

Working on participatory prevention communication, starting from the construction and sharing of social representations and social imaginary, is a pretty unique perspective.

The process planning-social imaginary and social-engineering-communication of social representations, in fact, does not stop at the first change of the imaginary and social representations but continues if the contributions of groups of people and the points of view are activated and implemented in a systematic way. The result is a communicative planning that continues and is able to constantly renew itself, thereby increasing the participation and involvement of new groups of people.

The multiplication of participating groups has a positive effect on local communities. It is the participation in prevention communication projects that changes perceptions and actions, and therefore, also semantic maps. For example, if I want to change young people's relationship with alcohol, I have to try to rebuild their perceptions and their imaginary, submit them, and be ready to change them again in order to understand where to direct the communication and, especially, how to build it. You redraw the conceptual boundaries of some issues along with other social or individual identities not based on a simple argument but on a responsible involvement in the community or territory. It is a way of enhancing those roots within the vital world and common sense, of being in the world of everyday life that characterizes at least a part of civil society and the third sector.

\section{New prevention communication strategies}

If this is a plausible picture, what could the new communication strategies for organizations (public and nonprofit) interested in the change of social imaginary be? See figure 2

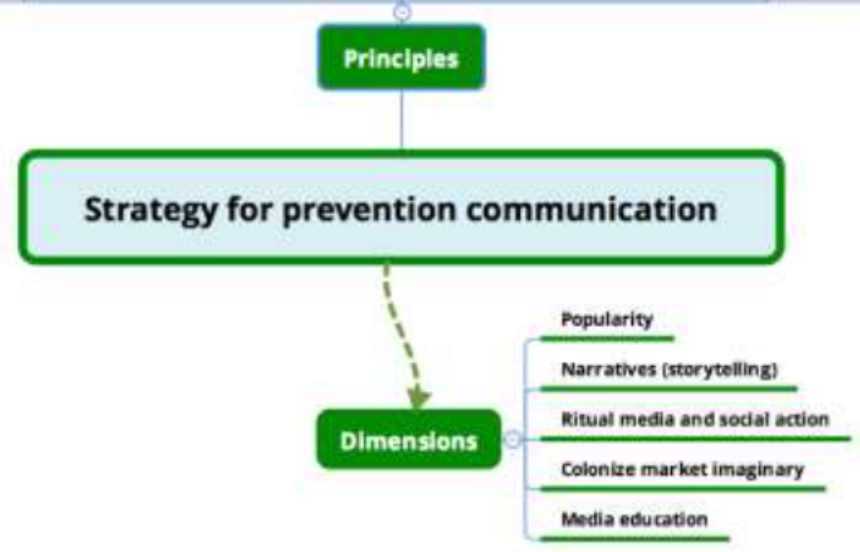

Figure 2 Strategy for prevention communication 


\section{Andrea Volterrani / From perception to change. A model for prevention communication}

a) Four principles

The first principle is monitoring the media public space daily - not only journalists, but also television (national and local) and the Internet - in order to be able to appropriate the narrative styles, symbologies, and prevalent proposals from major manufacturers of the imaginary. Mastering the mainstream is essential in order to build a prevention communication that goes beyond.

The second principle is reading the medial public space concerning social themes with detachment in order to highlight not only contradictions and shortcomings, but also symbols and rituals. Sometimes, some people talk about the absence of social and prevention issues without assessing their presence in narratives and imaginary places, such as the television series, which are rarely visited by the organizations (public and nonprofit) but often frequented by people and communities (Buonanno, 2008). A key prerequisite for any prevention communication project is the rebuilding of the media outlets with the topic of our interest.

The third principle is dealing with the operators of public space media (journalists, producers, writers, and directors) in order to understand dynamics, languages, styles, and working routines, especially with regard to the production of TV series and serials. It becomes a credible interlocutor when there is a need, for example, to construct new narratives by television writers. There are no permanent confrontation areas, and if there is a change in media narratives, it is related more to a transformation of the authors, writers, and scriptwriters than to an initiative taken by organizations.

The fourth principle is analyzing and continuously monitoring the issue which is our membership organization's subject of interest, and then to go and explore different points of view away from it, to see and learn the ways that others learn the imagery of the subject that interests us. We will be surprised by how the social imaginary also extend to those who are most distant from those other individuals who are fully involved in communication actions on the subject.

b) Five aspects of a prevention communication strategy

Based on these principles, how we can build a sensible strategy in prevention?

There are five dimensions to consider as cornerstones. We must inspire communication actions to popularity that can be achieved if we put on the shoes of others (even when we do not like them) and share their thoughts and their imagination..

1) Putting yourself in the shoes of others. Put yourself in the "shoes" of the means of understanding the mechanisms, styles, languages, and popular places in the medial public space. Of course, you may think this means, for example, speaking to those who care about their own issue (the issue that directly affects them), e.g., people with disabilities caring about other people with disabilities or the operators who deal with disabilities. They are important information and communication functions, but if I want to implement a process of change, I must listen to those who are furthest away from disability and may not even want to hear about it. You may miss something, even so, in the richness and articulation of contents to acquire breadth (and depth) of communicative action. We must not forget that rooted popular stereotypes are not very rich or articulated in terms of information, but they are widely present in the mainstream and often right on prevention issues. Building popular prevention communication does not mean trivialization and simplification of the messages and content, but that messages and content can be decoded and interpreted by many.

2) Looking for narratives. Narratives are the second important dimension of our strategy. Human life, history and biography, is our first story. The narrative approach (Bruno, Lombardinilo, 2016) to prevention communication means not only finding stories in the media, but gaining the ability to discover, collect, and analyze stories, and then invent, build, and commission new ones, representatives for the community. Stories 
must not appeal only to us, because the stories become narratives if we tell them to others and if others hear them. In addition, we must always keep in mind that there is only the "reality" or the "real" in the stories. The likelihood is that only one is possible and credible from among multiple realities (Schutz, 1972), and a story is deemed credible only if we share it with others. In summary, it is not important to build large, detailed stories, but instead to draw from the "mines of the stories" in the social and prevention life, as well as from those that are already present in other corners of the collective imagination.

3) Rituals. The third dimension is the ritual. Our daily life is full of large and small rituals of which we do not want to do without. For this purpose, ritual also means proposing familiar actions and communication (Couldry, 2012, p. 80). The question we must ask is, "What creates meaning in my land and communicative context?" The question, though, is that very often what creates meaning is "taken for granted" and is silent since it works from a cultural background that determines common sense. The ritual dimension, by contrast, is a dimension that, behind the apparent static repetition of common sense, can intervene in imagination, modifying it. In practice, it means being systematically reproduced and easily identified by the inhabitants of a territory of prevention communication activities without fear of being "repetitive" because one of the goals is just that.

4) Colonize the collective imagination (Peruzzi, Volterrani, 2016, p. 220). The fourth dimension is that of colonization to which we referred earlier. Imaginary proposed by the actors who act in the market are not "evil" and, above all, make up the central part of the frame; they are the most widespread and popular, and also the most democratic. The profit actors are appropriate in a time of popular social imaginary, which considered using them to expand or build new market space. As a counterpoint, third sector organizations or public organizations could do the same using widespread and used imaginary as part of the market to promote new social imaginary. This does not mean the flattening of market strategies or transfer of cultural patterns prevailing in the market, but recognizing what are now standard in the archive of images and imaginary and using them by offering an intelligent and creative remix that can support different but contiguous perspectives.

5) Educate the media. Finally, the last dimension refers to media education (Buckingham, 2003). Despite the many paths of learning and spread of pedagogical aspirations of many of the social issues of most organizations, the potential of sharing common media education is not perceived, not only in the context of the school and young people, but also as one of the cornerstones of lifelong learning. It is through these medium- to long-term paths that people acquire the skills to understand, analyze, and individually and collectively build media culture, thereby helping to build cultures and innovative collective imagination.

\section{The communication campaign, "I do take risks": a best practice}

"Terremoto-Io non Rischio" is a national campaign to reduce seismic risk, first launched in 2011. The campaign is now in its fifth edition in 230 Italian districts, most of them classified as Type 1 and 2 areas, which identify them as being at high and medium seismic risk. The campaign has been promoted by Civil Protection and A.N.P.A.S (acronym for "Association of National and Public Assistance") in partnership with Ingv (National Institute of Geophysics and Volcanology) and ReLuis (a web group made up of various university laboratories of physical engineering). The campaign aims to sensitize the population about earthquakes by attempting to spread information about the correct procedures to follow during seismic risk situations. The promoters of the campaign, attempting to increase citizen awareness and, with that, simplify the handling and acquisition of topics about earthquakes, have collaborated with properly trained volunteers. The campaign, "Terremoto-Io non Rischio" is carried out by groups of volunteers who, on special organized days, perform activities designed to sensitize the citizens of their communities.

The campaign is based on the principle of widespread diffusion: every single inhabitant is informed about seismic risks. That person then undertakes the responsibility of informing his/her relatives and others, who in turn inform the people they know and, by doing that, thus create a network of territorial relationships. 
The campaign provided training for over 2,000 volunteers who then trained another 10,000 volunteers on various topics (historical memory of areas; seismic nature of areas; dangerousness of areas and vulnerability of building estate; decrease of seismic risk; the role of the state and of the individual citizen in preventative action; how to communicate seismic danger, storytelling; and how to logistically manage the assigned town squares for the campaign).

If we compare the model with the campaign, we can observe some very interesting aspects. Firstly, with regard to perception, the actual presence in the town squares frequented by Italian citizens allows for the increase of the relevance of the theme through proximity and familiarity.

Secondly, with respect to knowledge, face-to-face interpersonal relationships allow for a thorough examination of the prevention theme.

Thirdly, the involvement of volunteers increases both the degree of trust and the sharing of language simplicity, thus favoring the incorporation of the themes of prevention.

Finally, the percentage of citizens who have changed their behavior after the campaign has increased by $35 \%$, an excellent result in a context such as the Italian one where little attention has formally been paid to prevention.

\section{Conclusion}

In conclusion, talking about prevention communication today means addressing the problem of cultural production.

Often many organizations and experts have underestimated this aspect because it has been deemed secondary to prevention or response action. An error which has been paid for dearly because, as we have seen, the space was occupied mainly by the market culture. The available space is limited, and it is difficult to act if approaches, prevention communication methods, and actions are not changed.

Precisely for this reason it is important to accept the challenge of innovation that lies in the ability to design prevention communication which has the means to promote and legitimize the growing presence in the available media space through fascinating and diffusible products and credible narratives,.

The hope is that they do not remain only ideas, but instead become instruments of daily action in organizations that have social change at heart.

\section{Acknowledgements}

Thanks for this work go to the European project partners INDRIX that contributed to my reflections on communication for the prevention of natural disasters.

\section{References}

Bentivegna S., 2009, Disuguaglianze digitali (Roma-Bari: Laterza).

Bruno M., Lombardinilo A., 2016, Narrazioni dell'incertezza: società, media, letteratura (Milano: FrancoAngeli).

Buckingham D., 2003, Media Education: Literacy, Learning and Contemporary Culture (Cambridge: Polity Press).

Buonanno M., 2008, The Age of Television: Experiences and Theories (Bristol:Intellect Ltd).

Couldry N., 2012, Media, Society, World: Social Theory and Digital Media Practice (Cambridge: Polity Press). 
Proceedings of the $3^{\text {rd }}$ World Conference on Media and Mass Communication, Vol. 3, 2017 pp 82-90

Couldry N., Livingstone S., Markham T., 2010, Media Consumption and Public Engagement: Beyond the Presumption of Attention (New York : Palgrave Macmillan).

Curran J., 2011, Media and democracy (Londra: Routledge)

Dahlgren P., 2009, Media and Political Engagement: Citizens, Communication and Democracy (Cambridge: Cambridge University Press).

Dahlgren P., 2013, The Political Web: Media, Participation and Alternative Democracy (New York: Palgrave Macmillan).

Durand G., 1960, Les Structures anthropologiques de limaginaire, (Grenoble: Allier).

Hofstadter D., Sander E., 2015, Superfici ed essenze. L'analogia come cuore pulsante del pensiero (Torino: Codice Edizioni).

Horsley J.S., 2016, Media framing of disaster. In: The Handbook of International Crisis Communication Research, edited by Schwarz A., Seeger M. W., Auer C. (Chichester: Wiley and Sons).

Jedloswki P., 2008, Immaginario e senso comune. In: Genealogie dell'immaginario, edited by Carmagnola F. Matera V. (Torino: Utet Università)

Martel F., 2010, Mainstream (Paris: Flammarion).

Murray C., Schrøder K., Drotner K., Kline S., 2003, Researching Audiences: A Practical Guide to Methods in Media Audience Analysis (London: Arnold Publications).

Peruzzi G. Volterrani A., 2016, La comunicazione sociale (Roma-Bari: Laterza).

Schutz A., 1972, Collected Papers I. The Problem of Social Reality (London: Springer).

Schwarz A., Seeger M. W., Auer C., 2016, The Handbook of International Crisis Communication Research (Chichester: Wiley and Sons).

Silverstone R., 1994, Television and everyday life (London:Routledge).

Vergani E., 2012, Costruire visioni (Roma: Exorma Edizioni).

Volterrani A., 2011, Saturare l'immaginario (Roma: Exorma Edizioni)

Volterrani A., 2016, How to Build Prevention for the Elderly and Disabled before Natural Disasters? The Added Social Value of Voluntary Organizations in Europe. Sociology and Anthropology 4 (2): 92-98 
